\title{
Title: Are we ready for virtual reality in K-12 classrooms?
}

\author{
Paola Araiza-Alba ${ }^{*}$ \\ paraiza@swin.edu.au \\ Therese Keane ${ }^{1}$ \\ tkeane@swin.edu.au \\ Jordy Kaufman ${ }^{1}$ \\ jkaufman@swin.edu.au
}

${ }^{1}$ Swinburne University of Technology, PO Box 218, Hawthorne, Victoria, Australia

\section{Authors e-mails}

*Corresponding Author: paraiza@swin.edu.au, Phone: +61392148822 


\begin{abstract}
Virtual reality technology has existed since the late 1950s; however, its use in the educational sector has been limited because of the cost of the equipment, inaccessibility of the technology, issues of usability, and lack of appropriate educational content and educator training. New technological advances have resolved some of these limitations. Additionally, affordable virtual reality equipment that has been predominately used with adults shows compelling results, highlighting the potential of this technology when used with children for educational purposes. This paper presents an overview of immersive virtual reality's potential as a learning tool with children, highlighting its current uses, research with children for educational purposes, and the existing barriers for the applicability and implementation of immersive virtual reality in school settings.
\end{abstract}

\title{
Keywords
}

Immersive virtual reality, educational technology, learning, K-12 education, limitations of IVR 


\section{Introduction}

With the rapid growth of technological advances such as high-speed computing, highresolution graphics, and interface devices, virtual reality (VR) technology has become not only an exciting gaming technology but also one with many potential new applications (Allcoat \& Adrian, 2018). Virtual reality is a three-dimensional (3D), computer-generated environment that leads the user to perceive the contents in a more realistic way. The person using this technology feels as though they are included in the artificial world and has the opportunity to execute physical actions and manipulate virtual objects (Smith, 2015).

Generating a computer environment that is hard to distinguish from the real world improves the user experience, compared to other types of media, and generates a high level of presence and motivation to use it (Urech, Krieger, Chesham, Mast, \& Berger, 2015).

Virtual reality technology opens the way to create an active learning environment where students can not only construct their knowledge through active participation, collaboration, and exploration but also where they can have fun while learning, resulting in a boost of students' engagement and attention during the learning process (Connolly, 2005; Farahmand, Yadav, \& Spafford, 2013). Studies have suggested that VR has the potential to be used as a pedagogical tool and as an immersive space for student learning, providing the learners with an authentic context where they can develop their scope of learning, visualize situations and concepts that are not possible to display on other mediums, and obtain more meaningful knowledge (Chen, 2016; Huang, Rauch, \& Liaw, 2010; Ibáñez et al., 2011)

Furthermore, people learn more and retain more when information is presented multiple times and through multiple channels, providing an opportunity to address the 'preferred' learning style of each student (Mayer, 2003). A VR system can present information multiple times using a range of delivery mechanisms and through multiple channels or senses. It is also highly auditory and visual, and more importantly, contains nonverbal auditory stimulus 
that traditional education methods do not have. Auditory cues, such as the sound of chemical reactions, or the sound of a objects falling to the floor, provide realism to the learning experience, allowing more understanding and practical learning, and resulting in higher levels of cognitive functioning (e.g., interpreting, analysing, discovering, evaluating, problemsolving, reflective thinking, and memorization) (Bell, Fogler, \& Arbor, 1995).

Another important aspect of VR is the capacity to present objects that are not usually visual or tangible in the real world, for example, walking around or inside the nucleus of a cell as it divides or looking inside a heart artery in biology class, or mathematical theories represented on a surface that students can walk on (Persky \& McBride, 2009). The ability to represent abstract concepts in a more tangible manner not only boosts the learning experience but generates students' engagement with the material. Theoretical concepts that are often dry and sometimes difficult to understand become easier to interact with and absorb.

Fulfilling the principles of constructivist learning is a significant outcome of this technology (Piaget, 1974). Constructivism is the theory that links learning with creating meaning from experience; the fundamental principles of this theory are interactive teaching strategies and the creation of a meaningful context that engages, motivates, and activates the construction of knowledge by the students (Piaget, 1974). Non-immersive and immersive VR (IVR) have the ability to satisfy these principles, giving students the opportunity to develop control over the content, sequence, and learning strategies to construct their own knowledge, as well as giving them authentic, contextual, and discovery activities to encourage diverse ways of thinking, generating an intrinsic motivation. These possibilities are feasible because of the sense of presence created in the computer-generated environment, which allows the participant to interact with the VR world in a more natural way that results in a better learning outcome (Ai-Lim Lee, Wong, \& Fung, 2010). Immersive VR provides higher levels of immersion by elevating the stimuli realism and making the user an active participant, 
which draws them inside the simulation as the virtual environment becomes completely enveloping and feels authentic (Persky \& Eccleston, 2011). These realism can lead to the enhancement of spatial cues and the development of an accurate mental map that could be used as a memory aid to learn complex procedures (Sowndararajan, Wang, \& Bowman, 2008).

While this technology has been predominately used with adults, some pilot studies and ongoing research are establishing the value of using IVR technology in different disciplines related to its use with children; however, these studies are not abundant (Gabyzon, EngelYeger, Tresser, \& Springer, 2016; Gershon, Zimand, Pickering, Rothbaum, \& Hodges, 2004; Passig, Tzuriel, \& Eshel-Kedmi, 2016). Furthermore, VR headset manufacturers provide a disclaimer that their products are not suitable for children under 12 or 13 years of age; however, they have not provided a rationale for this decision. The evidence to date confirms that this technology has potential as an educational tool, yet it does not validate the effectiveness of this technology with children.

For an overview of IVR's potential as learning tool, this paper will focus will be on describing the uses and conceivable applications of IVR technology with children in education, particularly the ideas behind its potential to be used as an educational tool, the most current uses of and research on IVR with children for educational purposes, and the constrains and limitations of its use in school settings.

\section{Virtual reality: the context}

\subsection{Historical background}

The term 'virtual reality' as a concept can be traced back to 1957 when Morton Heiling, a cinematographer, developed the Sensorama Simulator (Heilig, 1961) to stimulate the senses of the film audience and increase their engagement with the narrative. The Sensorama Simulator is one of the earliest known examples of immersive technology. The machine was 
able to display a wide field of vision, stereo sounds, smells, wind (produced by a fan), as well as vibration and body tilting through the seat to simulate motion (Srivastava, Chaudhury, \& Das, 2014).

The precursor to today's VR head-mounted display (HMD) was the Headsight System developed by Philco Corporation in 1961. The device contained a video screen corresponding to each eye of the user and a magnetic motion tracking system that was linked to a closedcircuit camera. The system was constructed for the military to provide helicopter pilots with a clear field of view while flying in the dark and to simulate dangerous situations in military operations (Srivastava et al., 2014)(Mazuryk, Gervautz, \& Smith, 2013). It was not until the late 80 s that the first commercially available VR device was created and the term virtual reality was coined (Dixon, 2006).

From 1970 to 1990 , VR was predominantly used for military training, industrial design, flight simulation, and medical purposes, but by 1994, gaming companies such as SEGA and Nintendo started to develop and commercialise consumer VR games (Mazuryk et al., 2013). Currently, many mainstream technology companies are developing VR-related products. The cost of the technology had seen a considerable decrease since 2013 when the new generation of consumer-priced VR technology was introduced by the company Oculus Rift (Jensen \& Konradsen, 2017). As VR technology has become more affordable and mainstream, schools are now considering it as a learning tool.

\subsection{Types of virtual reality systems}

The six types of VR systems use different equipment and tools to represent the virtual world and allow the user to interact with the environment (See Table 1). Despite the range and types of systems available, many listed in Table 1 cannot be used in school settings because the equipment is cost-prohibitive or they are not suitable for schools (i.e., vehiclebase). 
Immersive VR has gained popularity and is widely used in a variety of disciplines, such as education, healthcare, engineering, media, and military (Abulrub, Attridge, \& Williams, 2011; Allcoat \& Adrian, 2018; Bhagat, Liou, \& Chang, 2016; Rizzo et al., 2011). Immersive VR is a visual, multisensory, computer-simulated environment that perceptually surrounds an individual, leading the user to believe they have stepped inside or can interact with the generated world (Blascovich et al., 2002). The possibilities to create various stimuli, as well as the ability to maintain high experimental control and a high quality of realism, have made it useful for different purposes (Persky \& McBride, 2009).

Moreover, IVR is constantly evolving and, to date, the HMD is an essential component whereby users can view 3D computer-generated images within a helmet. The HMD uses an inertial and video tracking system to trace the position and orientation of a user's head, hands, or even the whole body by using special gloves, vest, or suit, which offers a compelling sense of personal, social, and environmental presence and provides a unique immersion experience (Blascovich et al., 2002). This equipment can also display and manipulate auditory, gustatory, haptic, olfactory, or thermal sensory stimulus (Persky \& McBride, 2009; Smith, 2015).

\section{The potential for IVR as a learning tool}

Exactly how well IVR will be able to fulfil its potential as an educational tool with children has yet to be determined since this technology is in its infancy and is an emerging educational technology (Bell et al., 1995; Southgate et al., 2019). To our knowledge, limited empirical studies have been published using fully immersive VR technology with children in K-12 school settings where its potential advantages and disadvantages are compared to more traditional technologies. However, so far, this technology has the potential to fulfil the basic requirements of a child's learning process. 
When used as an educational tool, IVR can challenge and overcome most of the limitations and difficulties of traditional technologies (e.g., two-dimensional (2D) media systems: books, TV, touchscreen devices, and computer), which typically have been described as impersonal, cold, and unsociable and have a learning transfer deficit that is more emphasised with children. The transfer deficit is defined as the difficulties that young children have to learn content from 2D media, compared with face-to-face interactions (Moser et al., 2015). The learning transfer deficit is attributed to the difficulties of encoding and translating 2D images onto a 3D object. For example, to encode and learn from a 2D media (i.e., TV), children need to translate what they are seeing as a 2D image or object to its real counterpart (3D object), which involves significant cognitive resources. When a child is trying to learn content presented through a screen, the objects and images on the screen are not only in a different dimension (2D) than the real objects (3D), but also degraded relative to the real objects (e.g. depth cues, shadow, colour, and gradients) making it harder for the child to assimilate and learn the content (Barr, 2010; Richert, Robb, \& Smith, 2011; Wilson, Soranzo, \& Sheffield, 2015). In contrast, the objects and images in an IVR environment are $3 \mathrm{D}$, so children do not need to use their cognitive resources to translate them to the real world, allowing them to instead use their mental resources to comprehend and learn the content.

However, some studies that suggest that children are able to apply knowledge acquired through media technology to their learning, as long as the content offers an active engagement with the educational task. Huber et al. (2016) found that children between 4 and 6 years are capable of transferring learning from touchscreen devices to real life and that interactivity plays an important role in children's learning. Similarly, Sommerville, Hildebrand, \& Crane (2008) found that infants can learn and solve a tool-use problem when they have the option to manipulate the tool while watching the instructions on video, 
compared with those who only watch other people using the tool. Manipulation of objects, interactivity, and active engagement seem to be key aspects when learning from media technology (Huber et al., 2016), aspects that are also key characteristics of the potentials of IVR systems.

Additionally, children between 3 and 8 years old use their entire body to experience their environment and all their senses to assist learning (Duhaney, Duhaney, \& Manley, 2008). The learning process occurs through play and exploration, and immersive VR offers the possibility to provide children with space to play, explore, and manipulate the environment, while also stimulating their senses through auditory, visual, and haptic cues. These characteristics are not possible with traditional technologies (e.g., television, video, computer, and touchscreen devices); therefore, IVR has a great potential as a learning tool.

Immersive VR offers the possibility of enhancing children's learning through active engagement, where students create their knowledge by doing, use their motor and cognitive skills, and receive frequent feedback, making the learning content easier to connect to its real-world context (Papanastasiou, Drigas, Skianis, Lytras, \& Papanastasiou, 2018; Roschelle, Pea, Hoadley, Gordin, \& Means, 2000). Moreover, this technology has the ability to combine a mix of teaching approaches (e.g., constructivism, problem-solving learning, discovery learning, etc.) that presumably can enhance learning outcomes and may present core concepts in less complicated ways (Liu, Bhagat, Gao, Chang, \& Huang, 2017). Other advantages of VR are the capacity of limitless repetitions for training purposes and that it may be a nondistracting and cost-efficient learning method (Alfalah, 2018). However, more empirical studies or clear evidence is required to show that students can learn using VR and then transfer the knowledge learned into real-life environments.

\subsection{Review of recent uses of IVR in education}

Until recently, IVR was quite novel and expensive to implement. As a result, not many 
academic studies have been performed using this technology with children in the educational field and, more specifically, using IVR for learning content with children in schools. At this time, the most common uses of IVR in education include virtual field trips, such as Google Expeditions and VR content developed by Mattel for use in early childhood. Other initiatives developing educational VR content for children are Nearpod and ImmersiveIT/ClassVR. Google Expeditions and Nearpod-VR leverage VR to present 360-degree images of cities or historical places to be used in the classroom. Children can experience virtual journeys by using a VR cardboard (a device to view VR) and a smartphone, while teachers guide the experience using a tablet device where they can show the interactive points of interest. Similarly, the View-Master VR from Mattel and ImmersiveIT/ClassVR offer 360-degree environments where children can visit and learn about space, ocean, science, wildlife, dinosaurs, and exciting destinations such as the great wall of China.

While IVR educational content can be used for learning purposes, scientific studies are lacking that test the effectiveness and adaptability of this content with children or in school settings. The majority of studies where IVR is used for educational purposes are with students in postsecondary school (Freina \& Ott, 2015; Han, 2019; Loup, Serna, Iksal, \& George, 2016), and the studies are normally conducted in clinical settings or laboratories (Southgate \& Smith, 2017). Some of the content where IVR is used in an educational context (postsecondary school) includes anatomy (Choi, He, Chiang, \& Deng, 2015; Kulcsár et al., 2013), maths (Kaufmann, Schmalstieg, \& Wagner, 2000), architecture and design (Ângulo \& Velasco, 2013), skills training (Fallis, 2013; Persky \& Eccleston, 2011; Reiners, Wood, \& Bastiaens, 2018), and language learning (Schwienhorst, 1998). Nevertheless, a few recent studies have been trying to demonstrate the potential benefits of IVR with children in education. However, these studies encounter some limitations such as small sample sizes, subjective learning measurements, or the lack of control groups. 
Below, we present a review of recent academic papers that investigate the use of IVR with children in education. This review followed four inclusion criteria: the studies must 1. evaluate children (under 18 years), 2. use IVR (using a headset) for educational purposes, 3. evaluate the effect of IVR in learning, and 4. have been published in the last two years. The search strategy was devised through scoping the literature for keywords indexed in published journal articles using the terms: ('Virtual reality') AND (learning) AND (education) AND (schools) AND (children). Our original search was conducted in May 2019 and was updated in December 2019. Papers that self-identified as pilot or feasibility studies were excluded. We searched SCOPUS and ERIC, which produced 135 results after removing duplicates. The inclusion criteria were applied to these papers, resulting in five studies that satisfied all criteria. Most of the excluded studies were either conference papers, did not use an immersive VR system, or did not use IVR for educational purposes.

In the study by Isabwe, Moxnes, Ristesund, \& Woodgate (2018), a small sample size of 16 children, aged 14 to 16 , participated to evaluate the learning outcomes of a chemistry class using IVR. Students had the opportunity to learn three different chemical concepts/interactions: the results of the interaction between gasoline, heat, and oxygen (e.g., participants experienced the chemical reaction when gasoline is thrown into a campfire).; the interaction of liquid nitrogen and boiling water; and the dangers of carbon monoxide. All students were immersed in the VR environment and performed a series of experiments to test the different chemical reactions. Qualitative results showed that students increased their understanding of complex chemistry concepts while maintaining high levels of engagement during the learning process.

Demitriadou (2019) compared the effectiveness of IVR and augmented reality versus traditional teaching methods to teach maths to primary school children. As part of this study, 30 children aged 9 to 11 years were divided into three groups: a control group that learned 
about geometric solids with a traditional paper worksheet and two experimental groups that used IVR or augmented reality to learn the same content. The results indicated that children in the two experimental groups, VR and augmented reality, improved their learning and understanding of mathematical concepts more efficiently than participants using the traditional method.

To determine the potential uses and effectiveness of IVR on children's learning when used in a school setting and not in experimental settings, we found four studies: the case study by Cheng (2019) and the studies by Han (2019), Karkar, Salahuddin, Almaadeed, Aljaam, \& Halabi (2018), and Bolier, Hürst, Van Bommel, Bosman, \& Bosman (2018).

In the case study by Cheng (2019), 24 children (9-12 years old) participated in a virtual field trip as part of teaching subjects of social studies. The topic was the World War II field trip from Google Expeditions. All participants learned about the military attack on Pearl Harbor using the VR headset, and then their motivation, sense of presence, and learning attitudes, as well as the interaction between teacher and student, were measured. The results showed that students' motivation was generally enhanced, and their sense of presence was strong, and the teacher-student interaction resulted in a typical exchange where questions and answers frequently happened throughout the virtual field trip experience. Although these results are part of the emerging area of pedagogical research looking into the use of virtual reality in the classroom, the study did not measure learning outcomes and did not compare the effects of VR with more traditional learning methods.

Similarly, Bolier, Hürst, Van Bommel, Bosman, \& Bosman (2018) investigated the potential benefits and obstacles of IVR 3D drawing for art education at an elementary school. Eighteen students aged 10-12 years old participated in the study. The IVR experience required students to complete a series of 2D and 3D drawings using an HMD, moving their body to produce different angle perspectives as part of their drawings. Results showed that 
children quickly improved at drawing 3D figures in the 3D IVR space and that the participants perceived the training exercise (step-by-step drawing content) as incredibly helpful. Due to the small sample size, the researchers were not able to infer conclusive results about the effect of the training exercises and the benefits of using IVR for drawing learning.

Finally, contrasting the studies above where no comparison groups were used, Han (2019) investigated the influence of IVR on sense of presence and perceived learning, comparing the results between IVR and a traditional medium (TV). Twenty-seven elementary-school children, aged 9-10 years, were invited to participate in the study. Participants explored two virtual field trip modules (San Diego Zoo and Reef Sharks) using a VR headset or using a regular TV. All participants experienced both modules with both media in different sequences, and their perceived levels of presence and learning with IVR and TV were compared. The results indicated an overall enhancement in virtual presence with the use of IVR. However, students reported learning less when using the IVR headset than when experiencing the modules with a regular TV. Even though the results of this study suggested practical implications for the use of IVR in educational settings, the learning results are only a perceived outcome rather than objective measurements of learning. In summary, although the few studies conducted with elementary-school children described above are the first attempts to understand the potential, effectiveness, and usability of IVR with young children, they possess some limitations such as small sample sizes, no comparison groups (e.g., traditional learning methods), were not done in a school setting, or did not objectively measure the learning outcome when students used IVR. Given that studies are limited and most them are aimed at students in postsecondary education, evaluating the potential of IVR as a learning tool for K-12 students is difficult. However, most of these studies could be used as a starting point to evaluate the effectiveness of IVR when applied to children. Therefore, robust scientific evidence with which to assess the effect, risks, 
advantages, and disadvantages of this technology and its implementation in school settings is vital if we want to wisely use this technology to its maximum potential and in a safe manner, not only because of its current accessibility on the market but also because IVR will be even more affordable and within reach of children over the next few years.

\subsection{Current barriers to the applicability and implementation of IVR in education settings}

As with any other type of emerging technology, uncertainties are associated with VR. The IVR equipment is still evolving, and its introduction in school settings is gradually being deployed. The premise for introducing VR into the classroom was based on the quality of the content and the recent affordability of the equipment (Jensen \& Konradsen, 2017). However, fundamental barriers such as physical constraints, ethical limitations, age restrictions, side effects, and organizational and educational limitations need to be addressed before the use of IVR in classrooms becomes normalised.

\subsection{Physical constraints}

The more immersive and interactive the environment, the greater the physical space required to use the equipment. Most IVR headsets require ample space around the user to allow them to freely engage with the experience and the environment. The simplest and cheapest version of a headset (VR cardboard) requires the user to move their head 360 degrees, while more interactive and sophisticated systems require larger amounts of space (e.g., HTC Vive $3 \mathrm{~m}$ by $3 \mathrm{~m}$ ) to allow the user to interact with the environment. Organisational structures of schools (typical classroom settings) do not often have the facilities to use this technology safely. If this technology is used in confined spaces, students may risk physical injuries, such as bumping into each other and into the walls. Another important aspect that is often overlooked involves the cables that connect the headset to the computer, which can cause physical harm such as a tripping hazard or strangulation. Hence, all VR manufacturers 
state that children must be supervised by adults while using wired VR equipment (D'Argenioe, 2016). Therefore, a set of safe operative procedures needs to be put in place before this technology can be used in a school setting.

\subsection{Ethical limitations}

Limited information or guidelines exist on the ethical use of IVR with children (Southgate et al., 2019). However, one line of ethical controversy regarding the use of IVR is its potential to trick the brain. Examples can be found in two different studies where the creation of false memories and posttraumatic stress disorder symptoms were generated using this technology. The first example, by Segovia \& Bailenson (2009), created false memories with children by using an IVR simulation. They watched an avatar of themselves doing two activities that they never did before, the first one was the child swimming with two orcas and the second was a child (avatar) shrinking to dance with a stuffed mouse. These two activities supposedly happened two years before the study, so the participants were told that they were two years younger when they did those activities. The children were interviewed five days after the experiment by a researcher who asked them if they remembered that they had swum with orcas and danced with a stuffed mouse. The researchers found that preschool and elementary-aged children were vulnerable to false memories.

Other risks involve the power to trick the subconscious brain into thinking that the user is really in the computer-generated world, and because of this, IVR can trigger some phobias such as fear of heights or darkness. It can also cause severe shock to users who are not expecting to confront or be exposed to their fears while they are at school. However, this technology can also be used in a safe and controlled therapeutic environment to treat patients with phobias (Korolov, 2014). Therefore, it is vital to ensure that the context of use is perceived as safe and that the content is designed to minimize emotional and physical discomfort (Jensen \& Konradsen, 2017). 


\subsection{Age restrictions and side effects}

Age restrictions imposed on VR technology by several manufacturers state that children over 12 or 13 years of age can use this technology. Google Daydream View, for example, is an affordable mobile headset with an advisory that states that this product should be used by people over the age of 13; other manufacturers such as Oculus Rift and Samsung also state a minimum age of 13 for their VR systems. Sony's PlayStation VR is not to be used by children under the age of 12, and HTC Vive does not state an age limit but warns against allowing young children to use the equipment. While age restrictions are advised, VR technology manufacturers have not provided a rationale for nor findings to support their disclaimers. Aubrey, Robb, Bailey, \& Bailenson (2018) stated that the manufacturer's age restrictions are in place because IVR is relatively new in the market and not much research has been done about long-term effects or long-term exposure, especially on children. This restriction poses a problem in using this technology with younger school age children in an educational context.

Mattel and Google produce both headsets and content geared towards children. Mattel, a multinational toy manufacturer, has developed a headset called View-Master Deluxe VR that, like Google's Cardboard headset, requires a mobile phone to view the VR content. Children from ages $7+$ can enter a virtual world such as a mysterious labyrinth, work with a friend to solve puzzles, help Batman defeat the villains, take a field trip to famous landmarks, explore natural ecosystems, interact with animals, and travel to space, amongst other experiences. Google has produced its simple headset using cardboard to assist with viewing VR content through mobile phones and has also produced content through Google Expeditions where teachers can take students on immersive, virtual journeys using this technology. Notably, some Google's content is distributed at no cost, and the cardboard headsets are relatively inexpensive. While Google's attempt at creating and delivering VR for classroom use has 
been welcomed, using the Google Cardboard is rather basic and rudimentary and does not have an age restriction, unlike other VR manufacturers do because of the sophisticated nature of their technology.

Side effects from using HMD with children can be categorised as short term and long term. The most common short-term side effects are motion sickness, eyestrain, headaches, and discomfort (discomfort could be more frequent in children because of the significant weight of the goggles) (Jensen \& Konradsen, 2017; Reid, 2002). In relation to the long-term effects, the general public is worried about health of children's eyes when using the VR headset for long periods of time. The American Academy of Ophthalmology (2017) stated that, while no long-term studies have been documented about the effects of VR on the eyes, a few things about the 3D image and the way that the VR headsets works would help us to understand the effects on the eyes. The HMD has the ability to mimic the way normal eyes work by showing a slightly different image to each eye, which enables the perception of depth. Additionally, the headsets are able to shift the picture in front of you as you look up, down, and side to side, making the experience more immersive and more life-like.

In a report by Yamanda-Rice et al. (2017), a preliminary study was carried out to address concerns about the possible negative effects on the children's eyes and balance when exposed to VR headsets. Twenty children aged 8 to 12 years old participated in the study where different standard eye and balance tests were performed before and after the use of a VR headset. Results showed that there was no difference between pre- and postscores on the standard vision test and that no difference was found in the postural stability test either. Therefore, the only risks known so far are the ones shared with adults (effects that are short term and recoverable), such as motions sickness, eyestrain, headache, migraines, discomfort, disorientation, nausea, and risk of colliding with the real world due to the lack of spatial awareness (crashing into a wall or bookshelf while immersed in the VR content). 


\subsection{Organizational limitations}

Most of the debate associated with the use, applicability, and implementation of IVR in schools or in different fields is related to technical, practical, and budgetary problems. From a technical perspective, the use of high-quality IVR has very specific system requirements that need not only a powerful computer but also constant software updates. Moreover, current IVR equipment is primarily used for entertainment rather than educational purposes; it was not designed for classroom use and requires a level of technical skills that can be a challenge for the average teacher (Jensen \& Konradsen, 2017; Vesisenaho et al., 2019).

As already mentioned, one of the major disadvantages of using VR in the K-12 classroom is the prohibitive cost of both the hardware and the content. In recent years, mainstream technology companies have introduced affordable IVR technology equipment making it accessible to the general public and researchers (e.g., Oculus Rift and HTC Vive). The cost to create high-quality VR content is still expensive, which is a barrier that limits the creation of new and specific content for education. Additionally, the use of IVR in any particular field requires higher programming or technical skills than traditional 2D tools; therefore, any school that plans to use this technology not only will have to outlay the cost of the equipment but also the training for their teachers to fully exploit the capacities of this technology (Huang et al., 2010).

\subsection{Educational limitations}

Four possible limitations could inhibit the use of IVR as an educational tool with students. First, IVR at the present time is mostly an individual experience, and some learning skills or concepts require social interaction to learn and practice (Kreijns, Kirschner, \& Jochems, 2003). Although making the experience with this technology a social experience is possible by creating collaborative tasks (e.g., a participant uses the headset while the other 
participants help the user from the outside by giving some advice on how to solve the task or what to do), the majority of the current content is designed for individual use.

The second limitation refers to textual information. Immersive VR is mostly an audiographical environment rather than a textual one; hence, presenting textual information is limited in some cases or for some core concepts that may be necessary, such as equations, formulas, or definitions. This limitation can be overcome delivering the visual and audio content through the VR environment and supplementing the VR experience with paper-based notes and activities, providing students with the experience needed for learning (Bell et al., 1995).

The third limitation has to do with the novelty effect of this new and emerging technology, which could play a crucial role in the engagement and learning process (Keane, Williams, Chalmers, \& Boden, 2017). Southgate et al. (2019) reported that this effect could be found when using IVR in educational settings; however, some students showed in-depth knowledge and greater engagement with the content when it was presented through IVR.

Lastly, the final limitation is about students' attention, with two points of view regarding the use of HMD to present information in the classroom. One view states that students could easily be distracted and not concentrate on one aspect when other tempting options are presented to the users in the field of view (Bell et al., 1995). Conversely, the use of HMD could help students focus on specific and relevant information because the field of view has specialized content and classroom distractions are eliminated, allowing the student to concentrate on the learning material (Southgate et al., 2019).

\section{Conclusion and Future Research}

The proliferation of new technology has opened exciting opportunities to enhance the way students learn, including increasing popularity of innovative IVR technology in classrooms. Immersive VR brings new possibilities to students, such as active engagement and 
exploration, and to teaching, such as the ability to combine a mixture of teaching approaches (e.g., problem-solving and discovery learning), as well as unlimited possibilities for the creation of stimuli. These benefits have led to the use of IVR in different disciplines that were never initially anticipated.

Based on research using IVR with adults, this technology can be useful for learning (Freina \& Ott, 2015). However, as limited studies have been performed with IVR and children, determining the effect when used in education is difficult (Srivastava et al., 2014; Wilson et al., 2015). While some evidence exists to support the advantages of VR in learning (Merchant, Goetz, Cifuentes, Keeney-Kennicutt, \& Davis, 2014; Mikropoulos \& Natsis, 2011), studies using IVR with children in schools is still very rare (Southgate \& Smith, 2017). Most of the academic papers that explore the use of IVR with children are in experimental or clinical settings and either do not compare IVR with traditional learning methods or use a small sample size (Bailey \& Bailenson, 2017a, 2017b; Freina \& Ott, 2015; Schwebel, McClure, \& Severson, 2014). Given the educational promise of this technology, more-supportive scientific research is needed to further investigate the advantages that IVR has over traditional learning methods (Huang et al., 2010; Mania \& Chalmers, 2001).

Previous research has demonstrated how IVR supports learning through identified factors, such as cognitive and emotional processes or individual students' differences (Merchant et al., 2014). However, before IVR can be used as an integral part of the educational curriculum, research is necessary to determine the levels of interaction required for learning specific concepts, which age groups could benefit most from this technology, how this technology enhances learning, and if this learning is transferable to daily life behaviours. Therefore, further research is needed on how and what K-12 children learn using this technology. Specific questions regarding implementation of IVR for education include:

- Does this technology have long-term effectiveness in learning? (Ke \& Im, 2013) 
- Which VR devices are most appropriate for learners?

- How should IVR technology be improved to meet learners' needs?

- What kind of IVR content will improve a learner's performance?

- Can IVR foster children's literacy and social-emotional development? (Huang et al., 2010)

- What support do teachers require to integrate this technology into their classrooms? (Vesisenaho et al., 2019)

Further questions about the technology need answering as well, particularly about design and ergonomics, such as lighter headsets suited for small heads, adjustable interocular measurements, and smaller controls that fit better in children's hands. Affordable, highquality IVR headsets are also required. Finally, production of quality educational content is essential, and while the use of IVR is an individual experience, thought needs to be given to the design of content to foster collaboration for deeper learning and understanding (Fawcett \& Garton, 2005). The inclusion of IVR in school settings as a normalised tool is gaining traction, and while this technology can be used for educational purposes, research to support the deployment of this technology in K-12 classrooms is much needed.

\section{Acknowledgements}

PAA express her gratitude to the Mexican National Council for Science and Technology (CONACYT) and to Swinburne University of Technology for research scholarship funding that supported this research.

\section{Conflict of Interest Statement}

The authors declare no conflicts of interest. 


\section{References}

Abulrub, A.-H. G., Attridge, A. N., \& Williams, M. A. (2011). Virtual reality in engineering education: The future of creative learning. 2011 IEEE Global Engineering Education Conference (EDUCON), 751-757. https://doi.org/10.1109/EDUCON.2011.5773223

Ai-Lim Lee, E., Wong, K. W., \& Fung, C. C. (2010). How does desktop virtual reality enhance learning outcomes? A structural equation modeling approach. Computers \& Education, 55(4), 1424-1442. https://doi.org/10.1016/j.compedu.2010.06.006

Alfalah, S. F. M. (2018). Perceptions toward adopting virtual reality as a teaching aid in information technology. Education and Information Technologies, 23(6), 2633-2653. https://doi.org/10.1007/s10639-018-9734-2

Allcoat, D., \& Adrian, von M. (2018). Learning in virtual reality: Effects on performance, emotion and engagement. Research in Learning Technology, 26(1063519), 1-13. https://doi.org/https://doi.org/10.25304/rlt.v26.2140

Ângulo, A., \& Velasco, G. V. de. (2013). Immersive Simulation of Architectural Spatial Experiences. Proceedings of the XVII Conference of the Iberoamerican Society of Digital Graphics - SIGraDi: Knowledge-Based Design, 495-499.

https://doi.org/10.5151/despro-sigradi2013-0095

Antonacci, D., DilBartolo, S., Edwards, N., Fritch, K., McMullen, B., \& Murch-Shafer, R. (2008). The Power of Virtual Worlds in Education : A Second Life Primer and Resource for Exploring the Potential of Virtual Worlds to Impact Teaching and Learning. ANGEL Learning, Inc, (July), 1-8.

Aubrey, J. S., Robb, M., Bailey, J., \& Bailenson, J. (2018). Virtual Reality 101: What you need to know about VR and Kids. 1-30.

Bailey, J. O., \& Bailenson, J. N. (2017a). Considering virtual reality in children's lives. Journal of Children and Media, 11(1), 107-113. 
https://doi.org/10.1080/17482798.2016.1268779

Bailey, J. O., \& Bailenson, J. N. (2017b). Examining Research with Children and Immersive Virtual Reality. Media Psychology. Retrieved from https://vrmaster.co/wpcontent/uploads/2017/02/bailey-jmp-children-and-IVR.pdf

Barr, R. (2010). Transfer of learning between 2D and 3D sources during infancy: Informing theory and practice. Developmental Review, 30(2), 128-154. https://doi.org/10.1016/j.dr.2010.03.001

Bell, J. T., Fogler, H. S., \& Arbor, A. (1995). The Investigation and Application of Virtual Reality as an Educational Tool. (2513), 1-11. Retrieved from http://www.cs.uic.edu/ jbell/Professional/Papers/aseepap2.pdf

Bhagat, K. K., Liou, W.-K., \& Chang, C.-Y. (2016). A cost-effective interactive 3D virtual reality system applied to military live firing training. Virtual Reality, 20(2), 127-140. https://doi.org/10.1007/s10055-016-0284-X

Biocca, F., \& Levy, M. R. (1995). Communication in the Age of Virtual Reality. Hillsdale, New Jersey: Lawrence Erlbaum Associates Inc.

Blascovich, J., Loomis, J., Beall, A. C., Swinth, K. R., Hoyt, C. L., \& Bailenson, J. N. (2002). Immersive Virtual Environment Technology as a Methodological Tool for Social Psychology. Psychological Inquiry, 13(2), 103-124. https://doi.org/10.1207/S15327965PLI1302_01

Bolier, W., Hürst, W., Van Bommel, G., Bosman, J., \& Bosman, H. (2018). Drawing in a Virtual 3D Space - Introducing VR Drawing in Elementary School Art Education. 337345. https://doi.org/10.1145/3240508.3240692

Chen, Y. L. (2016). The Effects of Virtual Reality Learning Environment on Student Cognitive and Linguistic Development. Asia-Pacific Education Researcher, 25(4), 637646. https://doi.org/10.1007/s40299-016-0293-2 
Cheng, K. H., \& Tsai, C. C. (2019). A case study of immersive virtual field trips in an elementary classroom: Students' learning experience and teacher-student interaction behaviors. Computers and Education, 140(June), 103600. https://doi.org/10.1016/j.compedu.2019.103600

Choi, K.-S., He, X., Chiang, V. C.-L., \& Deng, Z. (2015). A virtual reality based simulator for learning nasogastric tube placement. Computers in Biology and Medicine, 57, 103 115. https://doi.org/10.1016/j.compbiomed.2014.12.006

Connolly, P. E. (2005). Virtual Reality Immersive Technology in Education. International Journal of Information and Communication Technology.

D'Argenioe, A. M. (2016). VR SAFE FOR CHILDREN? Retrieved from GAMECREATE website: http://www.digitaltrends.com/virtual-reality/is-vr-safe-for-kids-we-asked-theexperts/

Demitriadou, E., Stavroulia, K.-E., \& Lanitis, A. (2019). Comparative evaluation of virtual and augmented reality for teaching mathematics in primary education. Education and Information Technologies. https://doi.org/10.1007/s10639-019-09973-5

Dixon, S. (2006). A history of virtual reality in performance. International Journal of Performance Arts and Digital Media, 2(1), 23-54. https://doi.org/10.1386/padm.2.1.23/1

Duhaney, D. C., Duhaney, B. D., \& Manley, E. (2008). Technology and young children Revisted.

Fallis, A. . (2013). Application of Virtual Reality Technology in Simulation of Automated Workplaces. Journal of Chemical Information and Modeling, 53(9), 1689-1699. https://doi.org/10.1017/CBO9781107415324.004

Farahmand, F., Yadav, A., \& Spafford, E. H. (2013). Risks and uncertainties in virtual worlds: An educators' perspective. Journal of Computing in Higher Education, 25(2), 
49-67. https://doi.org/10.1007/s12528-013-9067-5

Fawcett, L. M., \& Garton, A. F. (2005). The effect of peer collaboration on children's problem-solving ability. British Journal of Educational Psychology, 75(2), 157-169. https://doi.org/10.1348/000709904X23411

Freina, L., \& Ott, M. (2015). A Literature Review on Immersive Virtual Reality in Education: State of the Art and Perspectives. The Role of Internet in EducationChange and Transformation, 199-205. https://doi.org/10.12753/2066-026X-13-131

Gabyzon, M. E., Engel-Yeger, B., Tresser, S., \& Springer, S. (2016). Using a virtual reality game to assess goal-directed hand movements in children: A pilot feasibility study. Technology and Health Care, 24(1), 11-19. https://doi.org/10.3233/THC-151041

Gershon, J., Zimand, E., Pickering, M., Rothbaum, B. O., \& Hodges, L. (2004). A Pilot and Feasibility Study of Virtual Reality as a Distraction for Children With Cancer. Journal of the American Academy of Child \& Adolescent Psychiatry, 43(10), 1243-1249. https://doi.org/10.1097/01.chi.0000135621.23145.05

Han, I. (2019). Immersive virtual field trips in education: A mixed-methods study on elementary students' presence and perceived learning. British Journal of Educational Technology, O(0), 1-16. https://doi.org/10.1111/bjet.12842

Heilig, M. L. (1961). US patent 3050870A. Retrieved from https://patents.google.com/patent/US3050870A/en?oq=3\%2C050\%2C870

Huang, H.-M., Rauch, U., \& Liaw, S.-S. (2010). Investigating learners' attitudes toward virtual reality learning environments: Based on a constructivist approach. Computers \& Education, 55(3), 1171-1182. https://doi.org/10.1016/j.compedu.2010.05.014

Huber, B., Tarasuik, J., Antoniou, M. N., Garrett, C., Bowe, S. J., \& Kaufman, J. (2016). Young children's transfer of learning from a touchscreen device. Computers in Human Behavior, 56, 56-64. https://doi.org/10.1016/J.CHB.2015.11.010 
Ibáñez, M. B., Jesús, G. J., Sergio, G., David, M., Morillo, D., \& Delgado-Kloos, C. (2011). Design and Implementation of a 3D Multi-User Virtual World for Language Learning. Journal of Educational Technology \& Society, 14(4), 2-10. Retrieved from http://www.jstor.org/stable/jeductechsoci.14.4.2

Isabwe, G. M. N., Moxnes, M., Ristesund, M., \& Woodgate, D. (2018). Children's Interactions Within a Virtual Reality Environment for Learning Chemistry. https://doi.org/10.1007/978-3-319-60018-5_22

Jensen, L., \& Konradsen, F. (2017). A review of the use of virtual reality head-mounted displays in education and training. Education and Information Technologies, 23(4), 1515-1529. https://doi.org/10.1007/s10639-017-9676-0

Karkar, A., Salahuddin, T., Almaadeed, N., Aljaam, J. M., \& Halabi, O. (2018). A Virtual Reality Nutrition Awareness Learning System for Children. 2018 IEEE Conference on E-Learning, e-Management and e-Services, IC3e 2018, 97-102. https://doi.org/10.1109/IC3e.2018.8632634

Kaufmann, H., Schmalstieg, D., \& Wagner, M. (2000). Construct3D: A virtual reality application for mathematics and geometry education. Education and Information Technologies, 5(4), 263-276. https://doi.org/10.1023/A:1012049406877

Ke, F., \& Im, T. (2013). Virtual-Reality-Based Social Interaction Training for Children with High-Functioning Autism. The Journal of Educational Research, 106(6), 441-461. https://doi.org/10.1080/00220671.2013.832999

Keane, T., Williams, M., Chalmers, C., \& Boden, M. (2017). Involving everyone: Coding and decoding languages. IFIP Advances in Information and Communication Technology, 515, 579-588. https://doi.org/10.1007/978-3-319-74310-3_58

Korolov, M. (2014). The Real Risks of Virtual Reality. Retrieved from RIMS, The risk managment society website: http://www.rmmagazine.com/2014/10/01/the-real-risks-of- 
virtual-reality/

Kreijns, K., Kirschner, P. A., \& Jochems, W. (2003). Identifying the pitfalls for social interaction in computer-supported collaborative learning environments: a review of the research. Computers in Human Behavior, 19(3), 335-353.

https://doi.org/10.1016/S0747-5632(02)00057-2

Kulcsár, Z., O’Mahony, E., Lövquist, E., Aboulafia, A., Šabova, D., Ghori, K., ... Shorten, G. (2013). Preliminary evaluation of a virtual reality-based simulator for learning spinal anesthesia. Journal of Clinical Anesthesia, 25(2), 98-105.

https://doi.org/10.1016/j.jclinane.2012.06.015

Liu, D., Bhagat, K. K., Gao, Y., Chang, T.-W., \& Huang, R. (2017). The Potentials and Trends of Virtual Reality in Education. In Introduction: Virtual, Augmented, and Mixed Realities in Education (pp. 105-130). https://doi.org/10.1007/978-981-10-5490-7_1

Loup, G., Serna, A., Iksal, S., \& George, S. (2016). Immersion and persistence: improving learners' engagement in authentic learning situations. Lecture Notes in Computer Science (Including Subseries Lecture Notes in Artificial Intelligence and Lecture Notes in Bioinformatics), 9891 LNCS, 410-415. https://doi.org/10.1007/978-3-319-45153$4 \_35$

Mania, K., \& Chalmers, A. (2001). The Effects of Levels of Immersion on Memory and Presence in Virtual Environments: A Reality Centered Approach. 4(2), 247-264.

Mayer, R. E. (2003). The promise of multimedia learning: Using the same instructional design methods across different media. Learning and Instruction, 13(2), 125-139. https://doi.org/10.1016/S0959-47520200016-6

Mazuryk, T., Gervautz, M., \& Smith, K. (2013). Virtual Reality History, Applications, Technology and Future. Digital Outcasts, 63(ISIE), 92-98. https://doi.org/http://dx.doi.org/10.1016/B978-0-12-404705-1.00006-6 
Merchant, Z., Goetz, E. T., Cifuentes, L., Keeney-Kennicutt, W., \& Davis, T. J. (2014).

Effectiveness of virtual reality-based instruction on students' learning outcomes in K-12 and higher education: A meta-analysis. Computers and Education, 70, 29-40. https://doi.org/10.1016/j.compedu.2013.07.033

Mikropoulos, T. A., \& Natsis, A. (2011). Educational virtual environments: A ten-year review of empirical research (1999-2009). Computers \& Education, 56(3), 769-780. https://doi.org/10.1016/J.COMPEDU.2010.10.020

Moser, A., Zimmermann, L., Dickerson, K., Grenell, A., Barr, R., \& Gerhardstein, P. (2015). They can interact, but can they learn? Toddlers' transfer learning from touchscreens and television. Journal of Experimental Child Psychology, 137, 137-155. https://doi.org/10.1016/j.jecp.2015.04.002

Mukamal, R., \& Lipsky, S. (2017). Are Virtual Reality Headsets Safe for Eyes? - American Academy of Ophthalmology. Retrieved October 29, 2019, from https://www.aao.org/eye-health/tips-prevention/are-virtual-reality-headsets-safe-eyes

Papanastasiou, G., Drigas, A., Skianis, C., Lytras, M., \& Papanastasiou, E. (2018). Virtual and augmented reality effects on K-12, higher and tertiary education students' twentyfirst century skills. Virtual Reality, 23(4), 425-436. https://doi.org/10.1007/s10055-0180363-2

Passig, D., Tzuriel, D., \& Eshel-Kedmi, G. (2016). Improving children’s cognitive modifiability by dynamic assessment in 3D Immersive Virtual Reality environments. Computers and Education, 95, 296-308. https://doi.org/10.1016/j.compedu.2016.01.009

Persky, S., \& Eccleston, C. P. (2011). Impact of genetic causal information on medical students' clinical encounters with an obese virtual patient: Health promotion and social stigma. Annals of Behavioral Medicine, 41(3), 363-372. https://doi.org/10.1007/s12160010-9242-0 
Persky, S., \& McBride, C. M. (2009). Immersive virtual environment technology: a promising tool for future social and behavioral genomics research and practice. Health Communication, 24(February 2015), 677-682. https://doi.org/10.1080/10410230903263982

Reid, D. (2002). Virtual Reality and the Person-Environment Experience. Cyberpsychology \& Behavior, 5(6), 559-564.

Reiners, T., Wood, L. C., \& Bastiaens, T. J. (2018). New Landscapes and New Eyes: The Role of Virtual World Design for Supply Chain Education. Ubiquitous Learning: An International Journal, 6(1), 37-49. https://doi.org/10.18848/18359795/cgp/v06i01/40388

Richert, R. A., Robb, M. B., \& Smith, E. I. (2011). Media as Social Partners: The Social Nature of Young Children's Learning From Screen Media. Child Development, 82(1), 82-95. https://doi.org/10.1111/j.1467-8624.2010.01542.x

Rizzo, A., Parsons, T. D., Lange, B., Kenny, P., Buckwalter, J. G., Rothbaum, B., ... Reger, G. (2011). Virtual Reality Goes to War: A Brief Review of the Future of Military Behavioral Healthcare. Journal of Clinical Psychology in Medical Settings, 18(2), 176187. https://doi.org/10.1007/s10880-011-9247-2

Roschelle, J. M., Pea, R. D., Hoadley, C. M., Gordin, D. N., \& Means, B. M. (2000). Changing How and What Children Learn in School with Computer-Based Technologies. In Children and computer technology (Vol. 10).

Schwebel, D. C., McClure, L. A., \& Severson, J. (2014). Teaching children to cross streets safely: A randomized, controlled trial. Health Psychology, 33(7), 628-638. https://doi.org/10.1037/hea0000032

Schwienhorst, K. (1998). The 'third place' - virtual reality applications for second language learning. ReCALL, 10(1), 118-126. https://doi.org/10.1017/S095834400000433X 
Segovia, K. Y., \& Bailenson, J. N. (2009). Virtually True: Children's Acquisition of False Memories in Virtual Reality. Media Psychology, 12(4), 371-393. https://doi.org/10.1080/15213260903287267

Smith, J. W. (2015). Immersive virtual environment technology to supplement environmental perception, preference and behavior research: A review with applications. International Journal of Environmental Research and Public Health, 12(9), 11486-11505. https://doi.org/10.3390/ijerph120911486

Sommerville, J. A., Hildebrand, E. A., \& Crane, C. C. (2008). Experience matters: The impact of doing versus watching on infants' subsequent perception of tool-use events. Developmental Psychology, 44(5), 1249-1256. https://doi.org/10.1037/a0012296

Southgate, E., \& Smith, S. P. (2017). Designing and conducting research using immersive technologies in schools: Seven observations. 2017 IEEE Virtual Reality Workshop on K12 Embodied Learning through Virtual and Augmented Reality, KELVAR 2017, 1-3. https://doi.org/10.1109/KELVAR.2017.7961564

Southgate, E., Smith, S. P., Cividino, C., Saxby, S., Kilham, J., Eather, G., ... Bergin, C. (2019). Embedding immersive virtual reality in classrooms: Ethical, organisational and educational lessons in bridging research and practice. International Journal of ChildComputer Interaction, 19, 19-29. https://doi.org/10.1016/j.ijcci.2018.10.002

Sowndararajan, A., Wang, R., \& Bowman, D. a. (2008). Quantifying the benefits of immersion for procedural training. Proceedings of the 2008 ..., (January 2016), 2. https://doi.org/10.1145/1394669.1394672

Srivastava, K., Chaudhury, S., \& Das, R. (2014). Virtual reality applications in mental health: Challenges and perspectives. Industrial Psychiatry Journal, 23(2), 83. https://doi.org/10.4103/0972-6748.151666

Urech, A., Krieger, T., Chesham, A., Mast, F. W., \& Berger, T. (2015). Virtual reality-based 
attention bias modification training for social anxiety: A feasibility and proof of concept study. Frontiers in Psychiatry, 6(OCT), 1-6. https://doi.org/10.3389/fpsyt.2015.00154

Vesisenaho, M., Juntunen, M., Häkkinen, P., Pöysä-Tarhonen, J., Fagerlund, J., Miakush, I., \& Parviainen, T. (2019). Virtual Reality in Education: Focus on the Role of Emotions and Physiological Reactivity. Journal For Virtual Worlds Research, 12(1). https://doi.org/10.4101/jvwr.v12i1.7329

Wilson, C. J., Soranzo, A., \& Sheffield, S. (2015). The Use of Virtual Reality in Psychology : A Case Study in Visual Perception. Computational and Mathematical Methods in Medicine, 2015. https://doi.org/10.1155/2015/151702

Yamanda-Rice, D., Mushtaq, F., Woodgate, A., Bosmans, D., Douth-waite, A., Douthwaite, I., Whitley, S. (2017). Children and Virtual Reality: Emerging Possibilities and Challenges. Retrieved from http://digilitey.eu 
Table 1. Classification of VR systems

\begin{tabular}{|c|c|}
\hline Type & Description \\
\hline Window systems/computer-based VR & $\begin{array}{l}\text { A computer screen provides a window or } \\
\text { portal onto an interactive three-dimensional } \\
\text { (3D) virtual world. Desktop computers are } \\
\text { often used, and users sometimes wear 3D } \\
\text { glasses for stereoscopic effects. }\end{array}$ \\
\hline Mirror systems & $\begin{array}{l}\text { The user stares at a projection screen and } \\
\text { sees an image of themselves moving in a } \\
\text { virtual world. Video equipment is used to } \\
\text { record the user's body. A computer } \\
\text { superimposes a cut-out image on a } \\
\text { computer graphics background. The cut-out } \\
\text { images of themselves on the screen mirror } \\
\text { their movements, hence the name mirror } \\
\text { systems. }\end{array}$ \\
\hline Vehicle-based systems & $\begin{array}{l}\text { The users enter what appears to be a vehicle } \\
\text { (e.g., tank, plane, car, spaceship) and } \\
\text { operate controls that simulate movement in } \\
\text { the virtual world. The world is most often } \\
\text { projected on screens. The vehicles may } \\
\text { include motion platforms to simulate } \\
\text { physical movement. }\end{array}$ \\
\hline $\begin{array}{l}\text { Cave automatic virtual environments } \\
\text { (CAVE systems) }\end{array}$ & $\begin{array}{l}\text { Rear projection displays images in a room } \\
\text { or enclosure where the users are surrounded }\end{array}$ \\
\hline
\end{tabular}




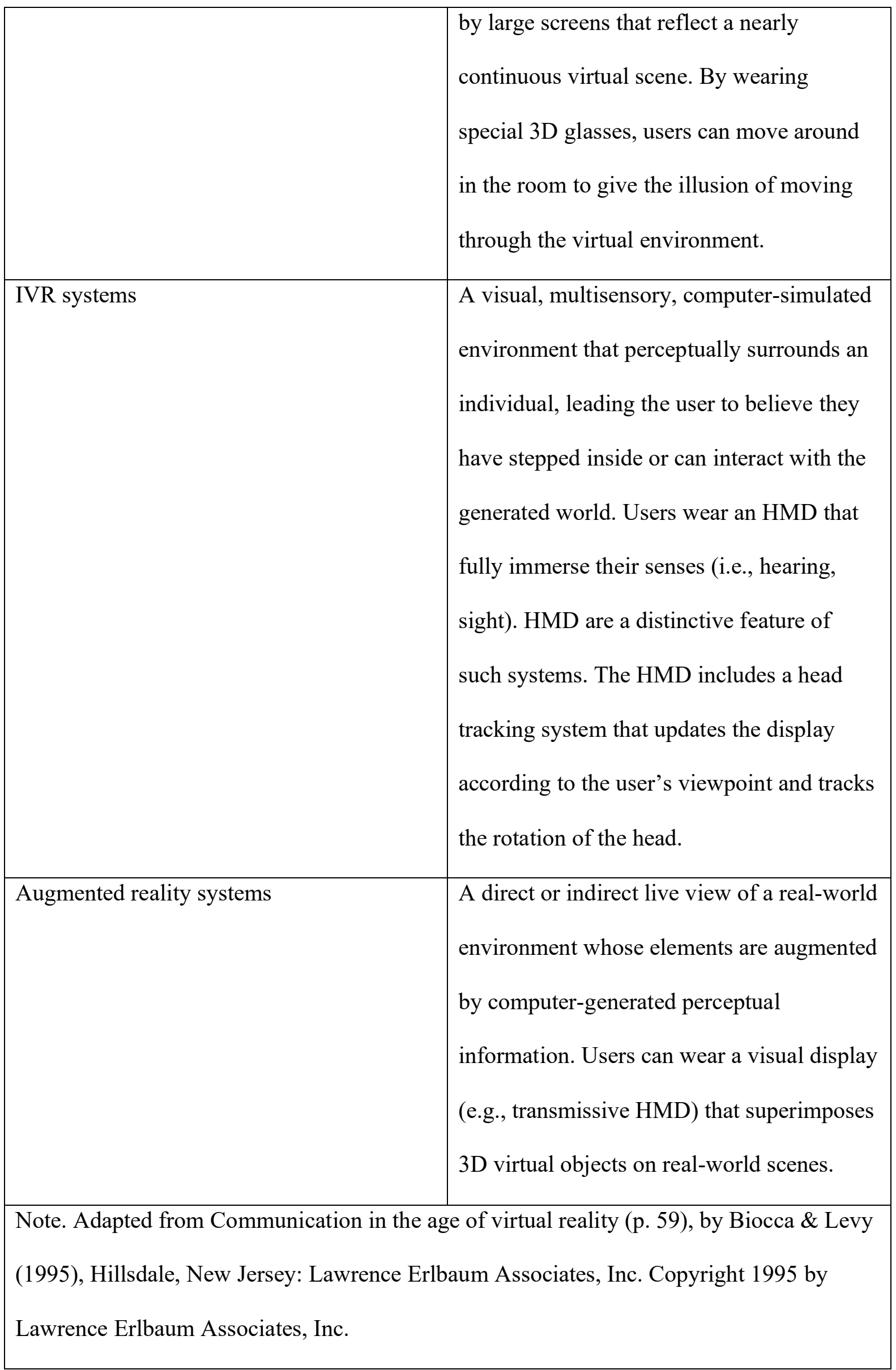


